\title{
Arbolapp, o com treballar amb el telèfon mòbil amb els alumnes de ciències naturals.
}

Silvia Leiva Hevia (sleiva3@xtec.cat) INS Lliçà d'Amunt (Lliçà d’Amunt).

Presentem una experiència d'ús del telèfon mòbil a l'aula per treballar les claus dicotòmiques i la classificació dels arbres amb alumnat de primer d 'ESO, fent servir una app. Amb aquesta activitat es pretén promoure la descoberta de l'entorn proper, l'observació $i$ el respecte per la natura i la implicació de la família a les activitats escolars.

Paraules clau: telèfon mòbil, app, clau dicotòmica, entorn,observació natura, família.

We present an experience about using of the mobile phone in classroom to work dichotomous keys and classification of trees with 1st year of Secondary School students, using an app. This activity pretends to promote students' discovering about environtment, observation and respect for nature, and family involvement in school activities.

Paraules clau: mobile phone, app, dichotomous key, environment, nature observation, family.

\section{FINALITAT I ORIENTACIONS}

Els nostres alumnes viuen molt pendents del seu telèfon mòbil (amb actituds gairebé de dependència vital), així que vaig decidir aprofitar aquest interès pel mòbil dels meus alumnes de primer de l'ESO per un objectiu educatiu. Per fer-ho, he dissenyat una seqüència didàctica que incorporés l'ús del telèfon mòbil, i l'he dut a terme durant el tercer trimestre del curs 2015/16. Segons el currículum que apareix a la LOMCE, les ciències naturals de 1r d'ESO han d'incloure tant continguts de Biologia com Geologia [1, 2], i en el nostre cas havíem decidit deixar la part de biologia per final de curs, ja que la primavera ens ajudaria a fer-la molt més motivadora i entenedora. També seria més fàcil trobar mostres i estudiar i gaudir del nostre entorn proper.

Amb els meus grups de $1 \mathrm{r}$ d'ESO, en sessions pactades, vam treballar amb els seus telèfons mòbils. Les directrius a seguir eren clares i concretes:

- Només es podia fer servir el telèfon quan jo deia que el podien agafar.
- Només per fer servir l'aplicació que necessitéssim per fer l'activitat en qüestió, les fotos i/o vídeos de l'experiment.

- No es podia gravar ni fer fotos a cap company sense els seu consentiment.

- No és podia fer servir un telèfon que no fos el seu.

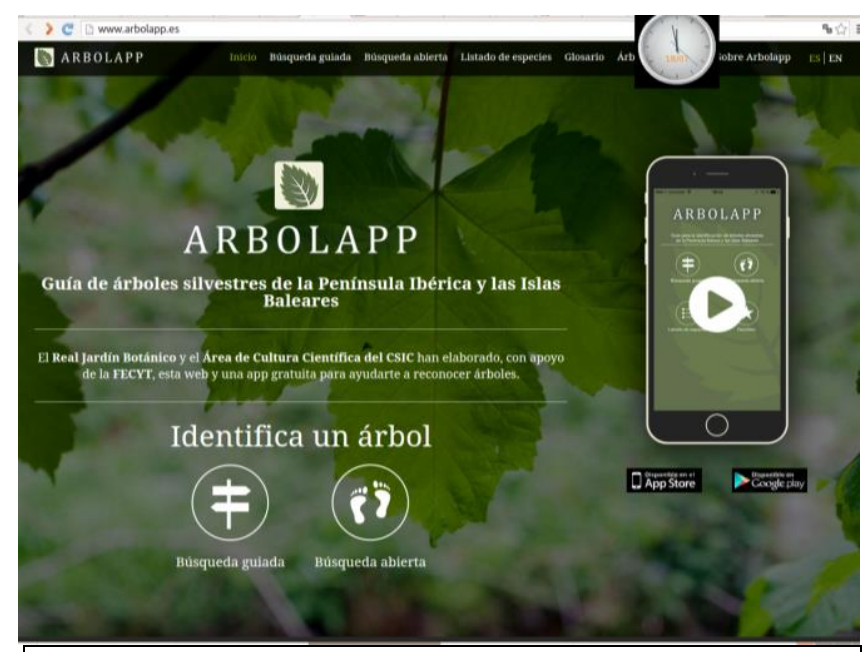

Figura 1: Pàgina web de l'aplicació on es pot descarregar l'app o treballar directament. 
A més de fer servir el mòbil quan realitzem observacions al microscopi o la lupa, per fer fotografies i/o vídeos, vaig donar un pas més i els hi vaig demanar que es descarreguessin una aplicació amb la que treballaríem una part del regne vegetal.

L'app amb la qual vam treballar es diu "Arbolapp" (Figura 1). Vàrem fer servir l'opció de cerca guiada que ofereix l'aplicació [3].

\section{CARACTERÍSITIQUES DE L'APP}

Arbolapp és una aplicació gratuïta creada pel CSIC per identificar 143 arbres silvestres de la Península lbèrica i Balears. Un cop descarregada a la Tablet 0 el mòbil ja no necessita connexió a internet, per la qual cosa podem treballar tranquil-lament al pati del institut o a la natura si som amants de les excursions.

Té un vocabulari científic però no massa tècnic, i aporta dibuixos i fotografies força entenedores que ajuden si en algun moment no tenim prou clar la decisió que hem de prendre.

\section{DESCRCRIPCIÓ DE LA SEQÜÈNCIA}

Abans de iniciar-nos amb aquesta aplicació havíem treballat a l'aula ordinària què era una clau dicotòmica, per què servia i com la havíem d'utilitzar. Per fer-ho, vam fer servir una fitxa guió que els estudiants tenien disponible a l'aula virtual de ciències al Moodle de l'Institut, però igualment se'Is va facilitar en paper a classe, per realitzar l'activitat de forma conjunta. Desprès de llegir la fitxa, els estudiants van haver de descriure en gran grup i de forma oral els animals que apareixen, fent servir les característiques de classificació de la clau dicotòmica facilitada. A continuació es van repartir uns petit papers en blanc on havien de dibuixar un ésser inventat que tingués els caràcters que es feien servir a la clau dicotòmica, i finalment cada estudiant va mostrar el seu dibuix a la resta de la classe per tal que els companys el classifiquessin correctament.

En segon lloc, vam preparar el pati per treballar amb l'aplicació Arbolapp. Vam decidir quins arbres del pati faríem servir, i vaig penjar un rètol amb un número. Els quatre arbres que tenim a l'institut són Robinia pseudoacacia, Pinus halepensis, Olea europaea i Cupressus sempervirens (aquest últim no apareix a l'aplicació).

Amb Arbolapp ja al telèfon mòbil i amb una graella per omplir les característiques generals de ca- da espècie, l'alumnat, en grups de dos o tres, va passejar pel pati de l'institut cercant els rètols amb els números. Per cada arbre havien de trobar el nom científic, el nom «vulgar» en català i en casteIlà, i algunes observacions sobre les fulles, fruits o altres característiques que els hi cridessin l'atenció de cada arbre a investigar (Figura 2).

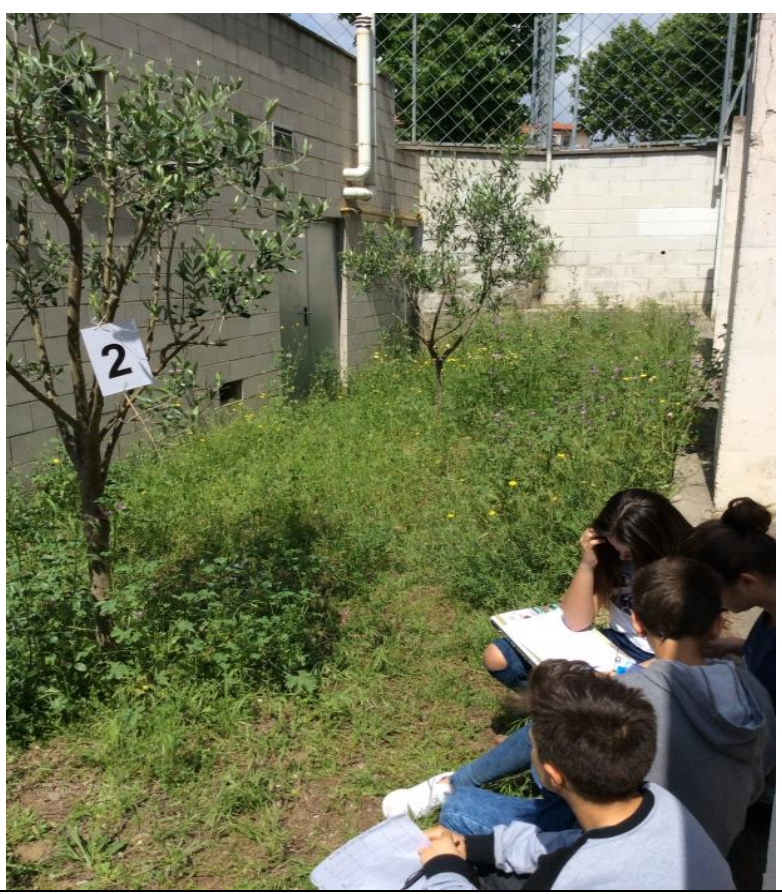

Figura 2: Grups treballant a l'ombra per classificar l'arbre número 2: Olea europaea.

Finalment, l'última activitat a realitzar i ja com a deures i fora del centre, va ser situar i classificar altres espècies d'arbres del nostre terme municipal. Es va demanar que ho fessin en família, i d'aquesta manera es demanava la implicació dels pares i/o germans. La demanda era que l'alumne expliqués el que feia i com ho feia a la resta de la família, i d'aquesta forma (explicant a altres aquest nou coneixement) prenia un protagonisme i desenvolupava millor les seves competències.

\section{VALORACIÓ DE L'ACTIVITAT}

En tots els grups amb els que vaig realitzar aquesta activitat la valoració per part dels alumnes ha sigut molt positiva. Els nois i noies van poder sortir de l'aula just quan el temps favorable els reclamava a l'exterior, i van treballar de forma autònoma pel pati. Va ser com una petita gimcana que els va motivar molt, i van millorar la seva capacitat d'observació, ja que la feina a entregar no era fer una fotografia sinó que havien de fer tot el procés de tria de decisions fins esbrinar quins arbres ens 
envoltaven. De vegades, sobretot al inici vaig haver d'orientar a diverses parelles quan es trobaven en un cul de sac, però inclús llavors ells mateixos em demanaven ajuda al adonar-se que la seva solució no corresponia amb l'arbre que tenien al davant (Figura 3). A més, quan alguna parella no havia acabat la feina durant la classe, la van poder entregar més tard durant el pati, ja que tant el telèfon com els arbres seguien disponibles.

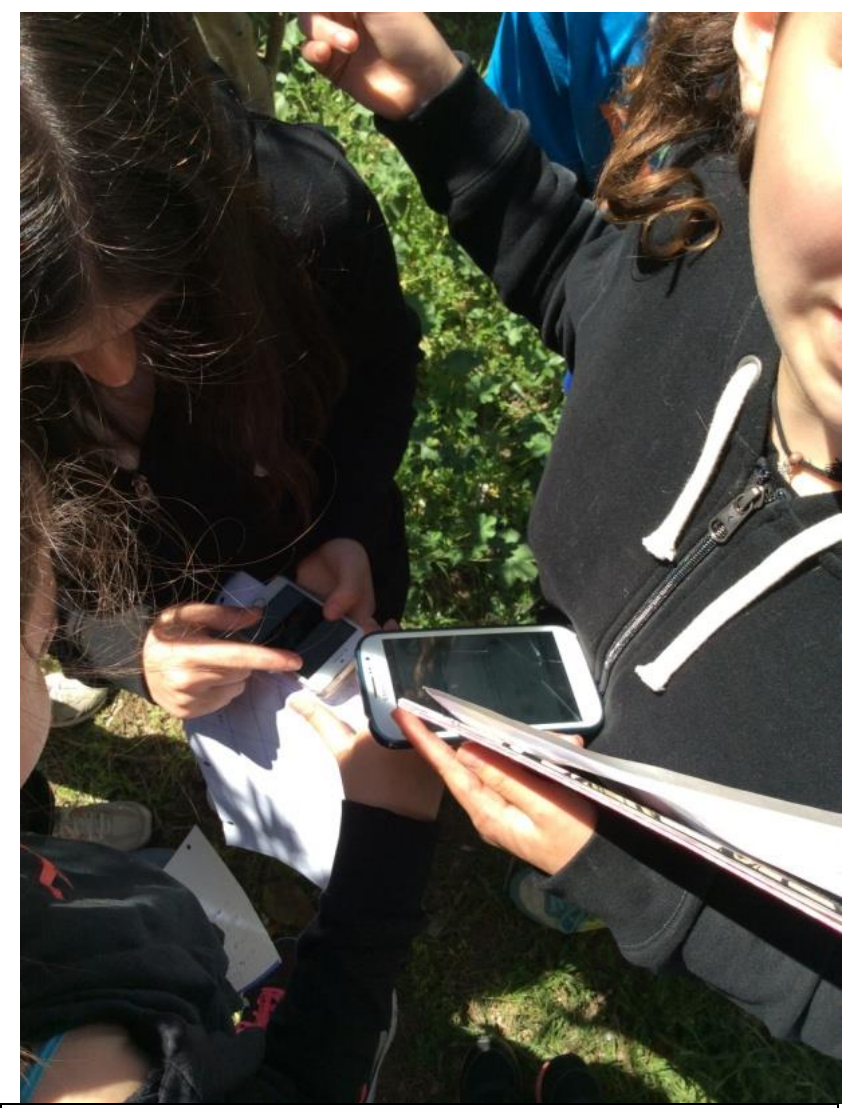

Figura 3: Alumnat demanant orientació: "El xiprer no surt a l'aplicació!"

Com a avantatges de l'aplicació des del punt de vista educatiu, destacar que aquesta promou la necessitat d'observació de l'alumnat, ja que requereix la continua pressa de decisions per saber davant de quin arbre es troba.
Com a inconvenients de l'aplicació, destacar que aquesta app només està disponible en castellà i anglès, però no en català, i, també, que només inclou arbres silvestres i no apareixen arbres que trobem normalment cultivats o arbres ornamentals.

La meva valoració personal coincideix amb la dels meus estudiants. Considero que activitats com aquestes permeten als estudiants treballar de forma autònoma però guiada, afavorint l'intercanvi d'idees, el consens i la pressa de decisions. També permet recuperat la implicació dels pares i mares en activitats escolars, tal com moltes famílies ho havien fet durant la primària. Al meu entendre, és important afavorir la comunicació i el temps en família en un curs escolar com és el $1 r$ d'ESO, ja que és un curs ple de canvis i adaptacions per part de tots els implicats.

\section{REFERÈNCIES}

SANMARTÍ, N., BURGOA, B. I NUÑO, T. (2012). ¿Por qué el alumnado tiene dificultad para utilizar sus conocimientos científicos escolare en situaciones cotidianas?. Alambique, 67, 62-69.

PAGÈS, E. (2011). La generació Google. De l'educació permissiva a una escola serena. Pagès Editors.

\section{NOTES}

[1] Currículum oficial de l'ESO [Consultat el 18 de juliol de 2016]:

http://xtec.gencat.cat/ca/curriculum/eso/curriculu $\mathrm{m} /$

[2] Currículum oficial de l'ESO en l'àmbit cientificotècnic [Consultat el 18 de juliol de 2016]: http://xtec.gencat.cat/web/.content/curriculum/es o/curriculum2015/documents/ANNEX-5-ambitcientifictecnologic.pdf

[3] Web de l'aplicació "Arbolapp" [Consultat el 18 de juliol de 2016]: http://www.arbolapp.es/ 